\title{
KONSEP DESAIN PENGELOLAAN DAN PEMELIHARAAN PRASARANA RUANG JALAN UMUM SESUAI STANDAR LAIK FUNGSI JALAN DAN STANDAR RUANG TERBUKA HIJAU KAWASAN PERKOTAAN
}

\author{
Suwardo $^{1}$, Heru Budi Utomo ${ }^{2}$ \\ ${ }^{1}$ D-IV Teknik Pengelolaan \& Pemeliharaan Infrastruktur Sipil, Dep. Teknik Sipil SV UGM, \\ Indonesia \\ Email: 1suwardo@mail.ugm.ac.id \\ ${ }^{2}$ D-III Teknik Sipil, Dep. Teknik Sipil SV UGM, Indonesia \\ Email: ${ }^{2}$ herubudiutomo@yahoo.com
}

\begin{abstract}
The objectives of the research are (1) to identify the infrastructure of green open space (RTH) concept on the road corridor, (2) to analyze the fulfillment of road space conditions against the requirements of road functional (SLFJ), (3) to analyze the completeness and condition of the road facilities to meet the green open space standard (SRTH), and (4) to set up development directives and design concepts for the management and maintenance of road space infrastructures that support green open space standards based on road functional requirements. Primary data for the analysis were obtained by direct observation/survey at the research site in Jalan Abu Bakar Ali, Malioboro, and Solo in Yogyakarta City and survey of respondents of road users with questionnaires. Secondary data used to support the analysis are (a) road map and condition of around study sites, (b) assumptions in design standards, (c) standards on markers, signs, lighting, drainage, and (d) related study reports. The method of quantitative and qualitative analysis according to SLFJ and SRTH was applied rationally. It can be concluded that the knowledge and perceptions of respondents about the use of road space and environmental conditions around the road in the three locations was obtained in Good category with scores of 3.4; 3.52; and 4.2, respectively. In Jalan Abu Bakar Ali respondents responded Agreed (score of 4.18), meaning that it required additional facilities and maintenance of the RTH's facilities and landscape. The management and maintenance of RTH's infrastructure and facilities of Jalan Abu Bakar Ali, Jalan Malioboro and Jalan Solo has been done by Yogyakarta City Planning Agency, organized and well-scheduled. Based on the evaluation of road functional requirement in Jalan Abu Bakar Ali (secondary collector), Jalan Malioboro (secondary artery), and Jalan Solo (secondary artery), all that are categorized as Conditional Function (LS). It means that the road has not fulfilled some road functional requirements in terms of utilization of road space, or there are still technical recommendations that must be met so that roads can be categorized as Function (LF). It obtained that Road Use Space (RUMAJA) is not effectively used, which characterized by still many permanent and non permanent buildings in the RUMAJA area. The design concept of the management and maintenance of road infrastructure should be based on the principle of maximizing road function (according to SLFJ) and the fulfillment of green open spaces on sidewalks and around (according to SRTH).
\end{abstract}

Keywords: road space infrastructure, design concept, management and maintenance, road functional requirement, green open space standard 


\section{PENDAHULUAN}

Jalan berfungsi untuk kelancaran lalulintas kendaraan, orang dan barang sehingga jalan harus memenuhi Standar Laik Fungsi Jalan (SLFJ). Disamping berfungsi untuk lalulintas, ruang jalan juga merupakan bagian dari koridor ruang terbuka hijau yang memanjang di suatu kawasan, sehingga ruang jalan juga seharusnya memenuhi Standar Ruang Terbuka Hijau (SRTH). Ruang terbuka hijau (RTH) merupakan salah satu komponen penting kawasan perkotaan, yang berupa bagian ruang-ruang terbuka (open space) yang dicirikan oleh adanya tumbuhan, tanaman dan vegetasi yang berfungsi sebagai perlindungan habitat tertentu atau sarana lingkungan kota guna mendukung manfaat sosial, budaya, dan arsitektural yang dapat memberikan manfaat bagi masyarakat. Permasalahan utama yang ada antara lain makin rendahnya kondisi ruang manfaat koridor jalan umum di kawasan perkotaan, yang belum sesuai dengan SLFJ dan SRTH.

Menurut UU No. 26 Tahun 2007 tentang Penataan Ruang dan Peraturan Menteri Pekerjaan Umum No. 05/PRT/M/2008 tentang Pedoman Penyediaan dan Pemanfaatan Ruang Terbuka Hijau di Kawasan Perkotaan disebutkan bahwa pengertian RTH adalah area memanjang/jalur yang penggunaanya bersifat terbuka, tempat tumbuh tanaman secara alamiah maupun yang sengaja ditanam. Dan disyaratkan luas RTH minimal 30\% dari luas wilayah (negara, provinsi, kota/kabupaten).

Ruang terbuka hijau memiliki manfaat yang sangat penting di dalam kawasan perkotaan. Jalan Abu Bakar Ali, Jalan Maliboro, dan Jalan Solo di Kota Yogyakarta merupakan kawasan jalan umum yang memiliki area hijau yang dapat dirasakan secara langsung seperti keteduhan dan udara yang segar. Topik penelitian tentang Evaluasi Pengelolaan dan Pemeliharaan Landscape Ruang Jalan Umum dalam Memenuhi Standar Kualitas dan Kuantitas Ruang Terbuka Hijau Kawasan Perkotaan. Maksud dari pengambilan topik tersebut adalah untuk mengetahui pengelolaan dan pemeliharaan ruang terbuka hijau dalam memenuhi standar yang mengacu pada aturan-aturan dan baku mutu di Indonesia.

Jalan Abu Bakar Ali, Jalan Maliboro, dan Jalan Solo di Kota Yogyakarta, Provinsi D.I Yogyakarta menjadi fokus penelitian, jalan ini merupakan jalan yang berada di tengah perkotaan yang terdapat berbagai pohon dan merupakan jalan utama menuju kawasan wisata utama kota Yogyakarta. Penelitian membahas tentang evaluasi yang lebih rinci kondisi area ruang terbuka di lokasi studi menurut standar laik fungsi jalan dan penyediaan ruang terbuka hijau di kawasan perkotaan. 
Berdasarkan latar belakang di atas maka dapat dirumuskan masalah dalam penelitian ini adalah: (1) Apakah koridor jalan umum pada lokasi studi kasus sudah sesuai standar RTH atau belum? (2) Bagaimana langkah penanganan evaluasi pengelolaan dan pemeliharaan RTH pada koridor Jalan Abu Bakar Ali dan koridor Jalan Solo dalam memenuhi standar kualitas dan kuantitas? dan (3) Bagaimana rekomendasi konsep desain prasarana/infrastruktur yang mendukung program pengelolaan dan pemeliharaan RTH pada koridor Jalan Abu Bakar Ali, Jalan Malioboro dan Jalan Solo?

Tujuan penelitian adalah 1) untuk mengidentifikasi prasarana pendukung konsep ruang terbuka hijau pada koridor jalan umum, 2) untuk menganalisis pemenuhan kondisi ruang jalan terhadap persyaratan standar laik fungsi jalan, 3) untuk menganalisis kelengkapan dan kondisi prasarana di ruang jalan untuk memenuhi standar kualitas dan kuantitas ruang terbuka hijau, dan 4) untuk menyusun arahan pengembangan dan konsep desain pengelolaan dan pemeliharaan prasarana/ infrastruktur ruang jalan umum yang mendukung standar ruang terbuka hijau berdasarkan persyaratan standar laik fungsi jalan.

\section{Klasifikasi Jalan}

Klasifikasi jalan menurut fungsinya meliputi (UU No. 38 Tahun 2004 Tentang Jalan):

1. Jalan arteri, merupakan jalan umum yang berfungsi melayani angkutan utama dengan ciri perjalanan jarak jauh, kecepatan rata-rata tinggi, dan jumlah jalan masuk (akses) dibatasi secara berdaya guna.

2. Jalan kolektor, merupakan jalan umum yang berfungsi melayani angkutan pengumpul atau pembagi dengan ciri perjalanan jarak sedang, kecepatan rata- rata sedang, dan jumlah jalan masuk dibatasi.

3. Jalan lokal, merupakan jalan umum yang berfungsi melayani angkutan setempat dengan ciri perjalanan jarak dekat, kecepatan rata-rata rendah, dan jumlah jalan masuk dibatasi.

4. Jalan lingkungan, merupakan jalan umum yang berfungsi melayani angkutan lingkungan dengan ciri perjalanan jarak dekat, dan kecepatan rata-rata rendah.

Klasifikasi jalan berdasarkan administrasinya meliputi (UU No. 38 Tahun 2004 Tentang Jalan):

1 Jalan Nasional, adalah jalan arteri atau kolektor yang menghubungkan antar ibukota provinsi dan jalan strategis nasional dan jalan tol.

2 Jalan Provinsi, adalah jalan kolektor yang menghubungkan ibukota provinsi dengan ibukota kabupaten atau kota, antar kabupaten dan jalan strategis provinsi. 
3 Jalan kabupaten adalah jalan lokal dalam sistem jaringan jalan primer yang tidak termasuk jalan yang menghubungkan ibukota kabupaten dengan ibukota kecamatan, antar ibukota kecamatan, ibukota kabupaten dengan pusat kegiatan lokal, antar pusat kegiatan lokal serta jalan umum dalam sistem jaringan jalan sekunder dalam wilayah kabupaten dan jalan strategis kabupaten.

4 Jalan kota, adalah jalan umum dalam sistem jaringan sekunder yang menghubungkan antar pusat pelayanan dalam kota, menghubungkan pusat pelayanan dengan persil, menghubungkan antar persil serta menghubungkan antar pusat pemukiman yang berada didalam kota.

5 Jalan desa, adalah jalan umum yang menghubungkan kawasan dan atau antar pemukiman didalam serta jalan lingkungan.

\section{Laik Fungsi Jalan}

Menurut Permen PU No.11/PRT/M/2010 laik fungsi jalan adalah kondisi suatu ruas jalan yang memenuhi persyaratan teknis kelaikan untuk memberikan keselamatan bagi penggunanya, dan persyaratan administratifnya yang memberikan kepastian hukum bagi penyelenggara jalan dan pengguna jalan, sehingga jalan tersebut dapat dioperasikan untuk umum.

Suatu ruas jalan umum dinyatakan sesuai dengan standar laik fungsi apabila memenuhi persyaratan teknis dan persyaratan administrasi. Standar laik fungsi yang berdasarkan persyaratan teknis tersebut meliputi beberapa aspek berikut ini;

1. Teknis geometrik jalan,

2. Teknis struktur perkerasan jalan,

3. Teknis struktur bangunan pelengkap jalan,

4. Teknis pemanfaatan bagian-bagian jalan,

5. Teknis penyelenggaraan manajemen dan rekayasa lalu lintas,

6. Teknis perlengkapan jalan.

Kelaikan fungsi suatu ruas jalan dapat dinyatakan oleh 1 (satu) dari 4 (empat) kategori, yaitu:

1. Laik Fungsi (LF): Kategori Laik Fungsi adalah kondisi suatu ruas jalan, baik jalan baru maupun jalan yang sudah dioperasikan, yang memenuhi semua persyaratan teknis.

2. Laik Fungsi dengan Syarat Teknis yang Diturunkan (LT): Kategori Laik Fungsi dengan Syarat Teknis yang Diturunkan adalah kondisi suatu ruas jalan yang memenuhi sebagian 
persyaratan teknis Laik Fungsi Jalan, tetapi mampu memberikan keselamatan bagi pengguna jalan.

3. Laik Fungsi dengan Rekomendasi (LS): Kondisi Laik Fungsi dengan Rekomendasi adalah kondisi suatu ruas jalan yang termasuk dalam kategori laik fungsi bersyarat disertai rekomendasi teknis yang harus dipenuhi sesuai standar teknis yang berlaku.

4. Tidak Laik Fungsi (TL): Kategori Tidak Laik Fungsi Jalan adalah kondisi suatu ruas jalan yang sebagian komponen jalannya tidak memenuhi persyaratan teknis sehingga jalan tersebut tidak mampu memberikan keselamatan bagi pengguna jalan.

\section{Penentuan Rating Kondisi Perkerasan}

Kondisi perkerasan dianalisis dengan metode Pavement Condition Index (PCI) berdasarkan tujuh kategori kondisi seperti disajikan pada Tabel 1. Nilai kondisi diperolah dengan cara perhitungan $P C I$ dari data yang diperoleh dari survei yang telah dilakukan.

\begin{tabular}{ll}
\multicolumn{2}{c}{ Tabel 1. Nilai Kondisi Perkerasan Jalan } \\
\hline Nilai $P C I$ & Kondisi \\
\hline $0-10$ & Gagal (failed) \\
$11-25$ & Sangat buruk (very poor) \\
$26-40$ & Buruk (poor) \\
$41-55$ & Sedang (fair) \\
$56-70$ & Baik (good) \\
$71-85$ & Sangat baik (very good) \\
$86-100$ & Sempurna (excellent) \\
\hline
\end{tabular}

Sumber: Pavement Management for Airport, Roads and Parking Lots (Shahin, 1994) dalam buku Hary Christady Hardiyatmo (2015)

\section{Ruang Terbuka Hijau pada Koridor Jalan}

Ruang terbuka hijau (RTH) adalah suatu lapang yang ditumbuhi berbagai tetumbuhan, pada berbagai strata, mulai dari penutup tanah, semak, perdu dan pohon (tanaman tinggi berkayu); Sebentang lahan terbuka tanpa bangunan yang mempunyai ukuran, bentuk dan batas geografis tertentu dengan status penguasaan apapun, yang di dalamnya terdapat tetumbuhan hijau berkayu dan tahunan (perennial woody plants), dengan pepohonan sebagai tumbuhan penciri utama dan tumbuhan lainnya (perdu, semak, rerumputan, dan tumbuhan penutup tanah lainnya), sebagai tumbuhan pelengkap, serta benda-benda lain yang juga sebagai pelengkap dan penunjang fungsi RTH yang bersangkutan (Direktorat Jendral Penataan Ruang Departemen Pekerjaan Umum, 2006).

Peraturan Menteri No.1 Tahun 2007 tentang Penataan Ruang Terbuka Hijau Kawasan Perkotaan, Ruang Terbuka Hijau Kawasan Perkotaan yang disingkat RTHKP adalah bagian 
dari ruang terbuka suatu kawasan perkotaan yang diisi oleh tumbuhan dan tanaman guna mendukung manfaat ekologi, sosial, budaya, ekonomi dan estetika. RTHKP Publik adalah RTHKP yang penyediaan dan pemeliharaannya menjadi tanggung jawab Pemerintah Kabupaten/Kota. Pemanfaatan RTHKP publik dikelola oleh Pemerintah Daerah dengan melibatkan para pelaku pembangunan. RTHKP publik tidak dapat dialih fungsikan. Pemanfaatan RTHKP publik dapat dikerjasamakan dengan pihak ketiga ataupun antar pemerintah daerah.

Menurut Zoer'aini (2003), Ruang Terbuka Hijau di wilayah perkotaan merupakan bagian dari penataan ruang kota yang berfungsi sebagai kawasan hijau, pertanaman, hutan kota, rekreasi, olah raga, pemakaman, pertanian, pekarangan/halaman (green belt), dan lainya.

Hasni (2008), menyatakan yang dimaksud dengan jalur hijau (green belts) adalah daerah penyangga yang diproyeksikan di sekeliling batas (administratif) kota. Sabuk hijau penyangga umumnya berbentuk memanjang, bahkan bisa mencapai puluhan kilometer, namun jarak lebar jalur hijau ini relatif pendek, di mana ukuran pendek tidaknya tergantung pada kebutuhan yang disesuaikan dengan kondisi alam serta jenis kegiatan penduduk yang akan dilakukan di dalamnya.

Peraturan Menteri No.5 Tahun 2008 tentang penyediaan dan pemanfaatan ruang terbuka hijau dikawasan perkotaan. Ruang terbuka hijau pada pola ini ditempatkan tanaman antara 20\%-30\% dari ruang milik jalan (rumija) sesuai dengan kelas jalan. Jenis tanaman yang akan ditanam dipilih sesuai dengan fungsi dan persyaratan penempatan, dan disarankan memilih jenis tanaman khas daerah setempat. Pada tepi bagian jalan dapat berupa taman yang fungsi vegetasinya sebagai peneduh, penyerap polusi udara, peredam kebisingan, pemecah angin.

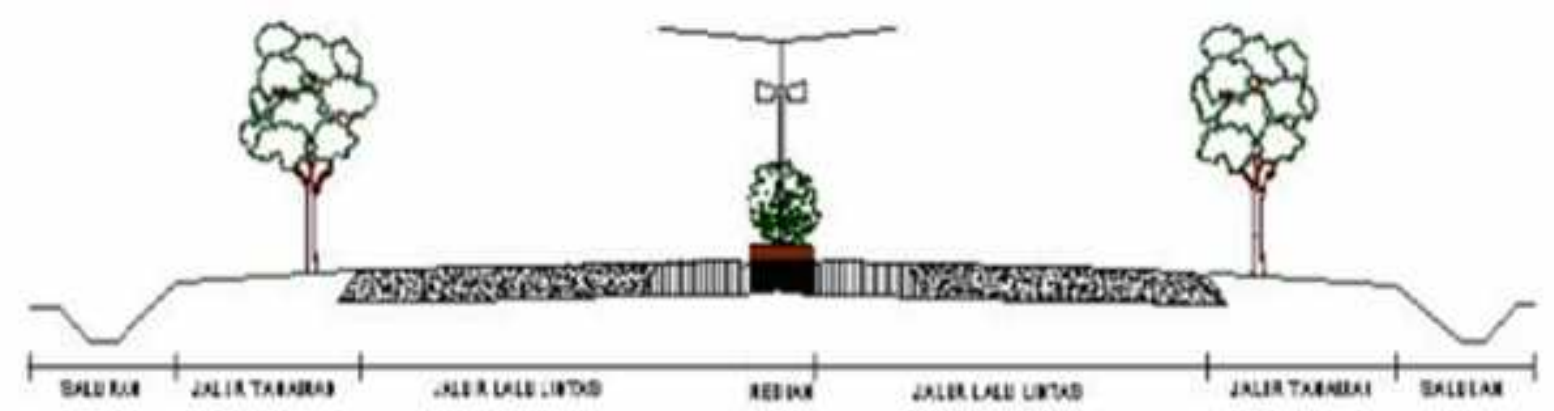

Gambar 1. Tata Letak Jalur Hijau Jalan

Sumber: Peraturan Menteri PU. NO. 5/PRT/M/2008 
Fungsi tanaman, meliputi:

1) Peneduh
a. Ditempatkan pada jalur tanaman (minimal 1,5 m dari tepi median).
b. Percabangan $2 \mathrm{~m}$ diatas tanah.
c. Bentuk percabangan batang tidak merunduk.
d. Bermassa daun padat.
e. Tidak mudah tumbang.

2) Penyerap polusi udara, peredam kebisingan, dan pemecah angin
a. Terdiri dari pohon, perdu/semak.
b. Memiliki kegunaan unruk menyerap udara
c. Jarak tanam rapat.
d. Bermassa daun padat.
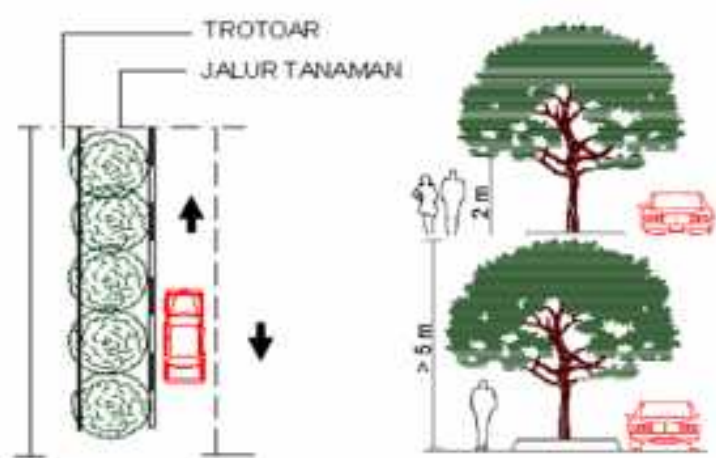

Gambar 2. Jalur Tanaman Tepi Peneduh Sumber: Peraturan Menteri PU. NO. 5/PRT/M/2008

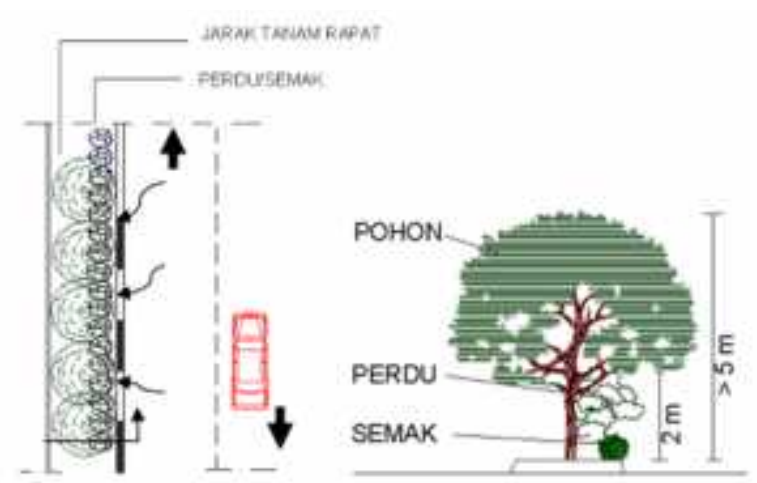

Gambar 3. Jalur Penyerap Polusi Udara Sumber: Peraturan Menteri PU. NO. 5/PRT/M/2008

\section{Ruang Terbuka Hijau untuk Pejalan Kaki}

Ruang pejalan kaki adalah ruang yang disediakan bagi pejalan kaki di sisi kiri maupun sisi kanan jalan. Ruang terbuka hijau ruang pejalan kaki harus memiliki kenyamanan, karakter fisik, serta pedoman teknis bagi pejalan kaki. Ruang pejalan kaki yang dilengkapi dengan RTH harus memenuhi hal-hal sebagai berikut :

1) Kenyamanan adalah cara mengukur kualitas fungsional yang ditawarkan oleh sistem pedestrian yaitu :

a. Orientasi berupa tanda visual (landmark, marka jalan) pada landscape untuk membantu dalam menemukan jalan pada konteks lingkungan yang lebih besar.

b. Kemudahan berpindah dari satu arah ke arah lain yang dipengaruhi oleh kepadatan pedestrian, kehadiran penghambat fisik, kondisi permukaan jalan dan kondisi iklim. 
2) Karakter fisik meliputi :

a. Kriteria dimensional, disesuaikan dengan kondisi sosial dan budaya setempat, kebiasaan dan gaya hidup, kepadatan penduduk, warisan dan nilai yang dianut terhadap lingkungan.

b. Kriteria pergerakan jarak rata-rata orang berjalan di setiap tempat umumnya berbeda dipengaruhi oleh tujuan perjalanan, kondisi cuaca, kebiasaan dan budaya.

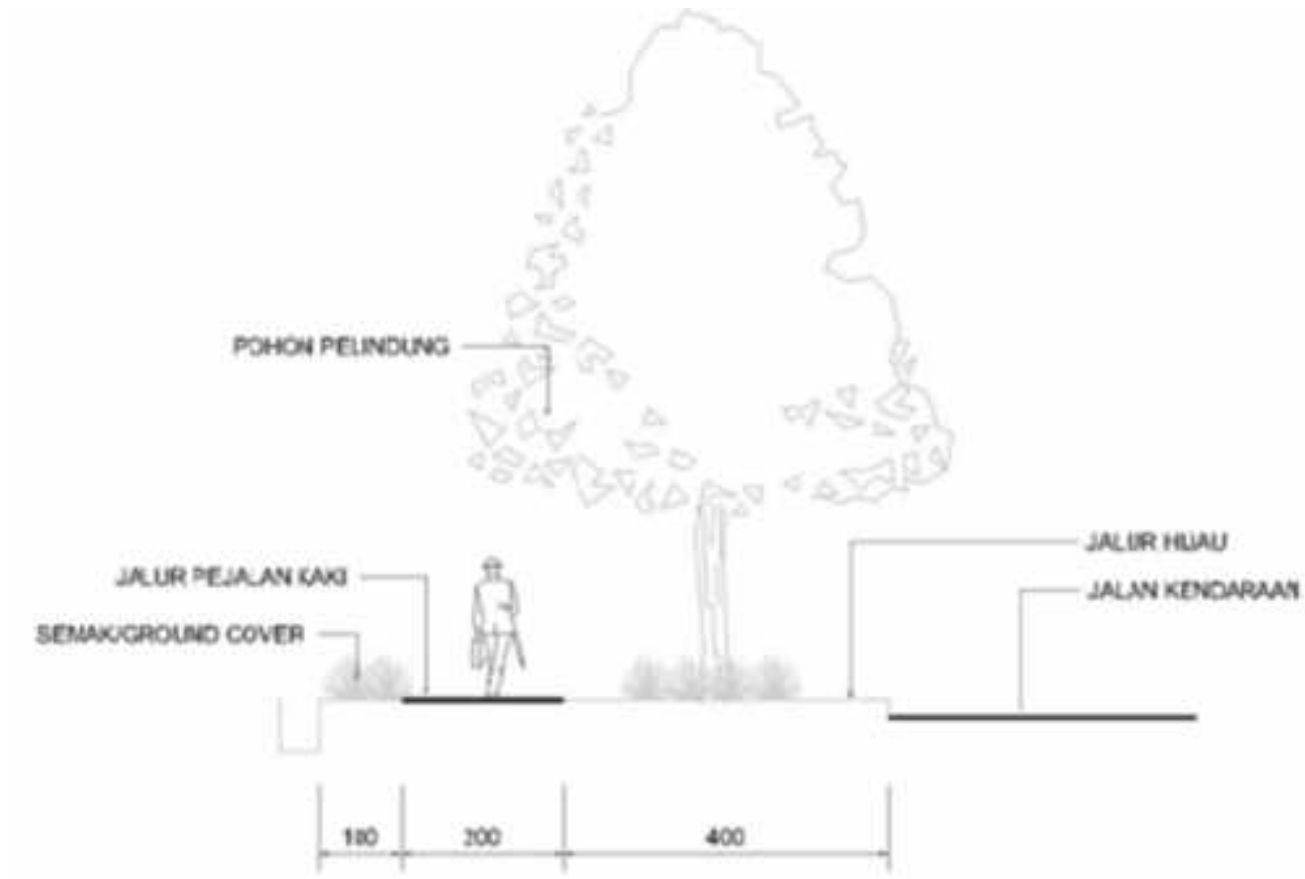

\section{Gambar 4. Pola Tanam RTH Jalur Pejalan Kaki} Sumber: Peraturan Menteri PU. NO. 5/PRT/M/2008

\section{Lanskap Jalan dan Pemeliharaan Tanaman}

Lanskap adalah wajah dari karakter lahan atau tapak yang terbentuk pada lingkungan jalan baik yang terbentuk dari elemen lansekap alamiah seperti bentuk topografi lahan yang mempunyai panorama yang indah maupun yang terbentuk dari elemen lansekap buatan manusia yang disesuaikan dengan kondisi lahannya. Lansekap jalan mempunyai ciri-ciri khas karena harus disesuaikan dengan persyaratan geometrik jalan dan diperuntukan terutama bagi kenyamanan pemakai jalan serta diusahakan untuk menciptakan lingkungan jalan yang indah, nyaman dan memenuhi fungsi keamanan.

Pemeliharaan tanaman dilakukan, meliputi:

1. Pemupukan

Prisip dasar pemupukan adalah mensuplai hara tambahan yang dibutuhkan sehingga tanaman tidak kekurangan makanan. Pupuk yang diberikan pada tanaman dapat berupa 
pupuk organik maupun pupuk anorganik (misalnya NPK atau urea). Pupuk yang digunakan untuk pohon-pohon tanam biasanya pupuk majemuk NPK.

2. Penyiraman

Tujuan penyiraman tanman, selain untuk menyeimbangkan laju evapotranspirasi, juga berfungsi melarutkan garam-garam mineral dan juga sebagai unsur utama proses fotosintesis. Waktu penyiraman pada dasarnya dapat dilakukan kapan saja saat dibutuhkan. Waktu penyiraman yang baik adalah pada pagi atau sore hari. Penyiraman siang hari hendaknya dilakukan langsung pada permukaan tanah, tidak pada permukaan daun tanaman. Untuk daerah dengan kelembaban tinggi penyiraman pada pagi hari lebih baik dari pada sore hari, dalam upaya menghindari penyakit yang disebabkan oleh cendawan.

3. Pemangkasan

Tujuan pemangkasan tanaman adalah untuk mengontrol pertumbuhan tanaman sesuai yang diinginkan serta menjaga keamanan dan kesehatan tanaman. Waktu pemangkasan yang tepat adalah setelah masa pertumbuhan generatif tanaman (setelah selesai masa pembungaan) dan sebelum pemberian pupuk.

\section{BAHAN DAN METODE PENELITIAN}

\section{Lokasi Observasi}

Lokasi penelitian adalah ruas Jalan Abu Bakar Ali, Jalan Malioboro, dan Jalan Solo di Kota Yogyakarta Provinsi D.I Yogyakarta seperti ditunjukan pada Gambar 5 s.d. Gambar 7.

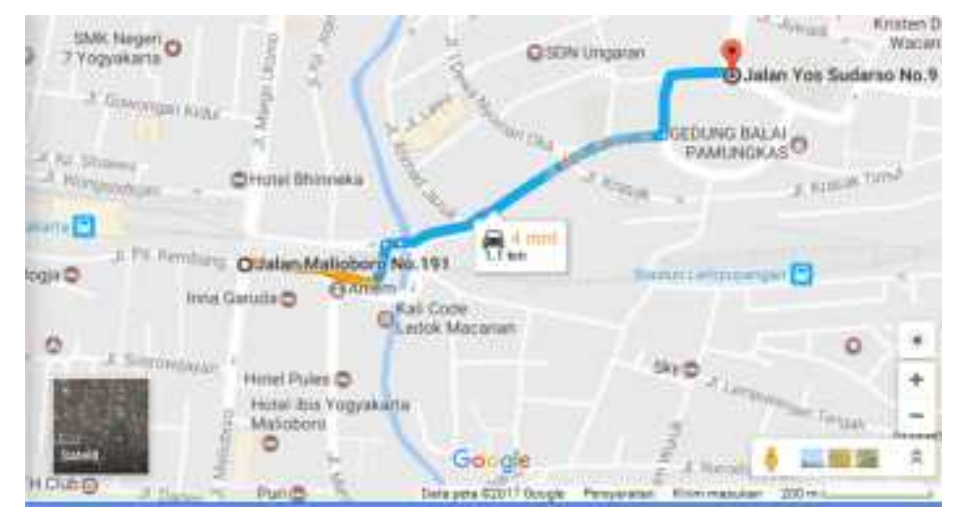

Gambar 5. Denah Lokasi Jalan Abu Bakar Ali (1,1 km) di Kota Yogyakarta Sumber: Google maps, 2017 


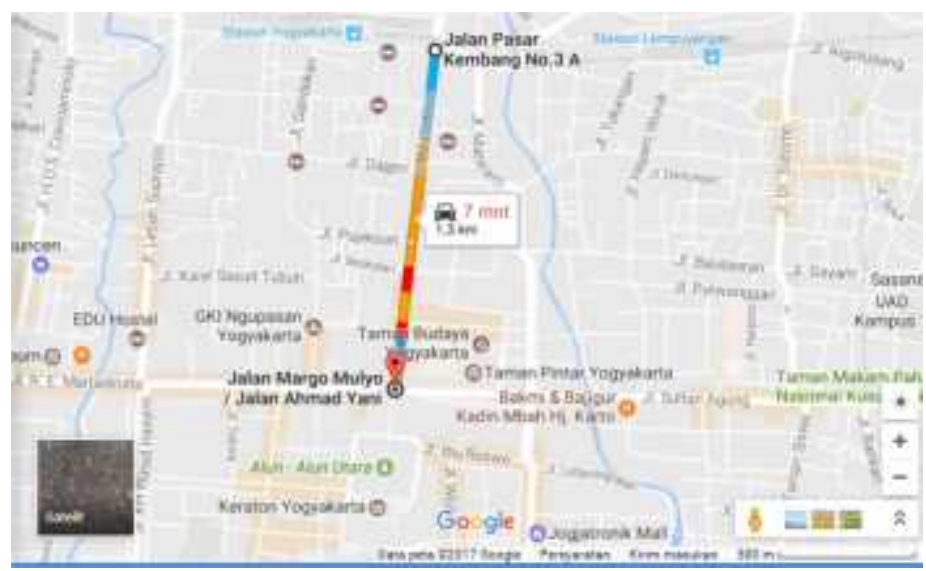

Gambar 6. Denah Lokasi Jalan Malioboro - Jl. A Yani (1,3 km) di Kota Yogyakarta Sumber: Google maps, 2017

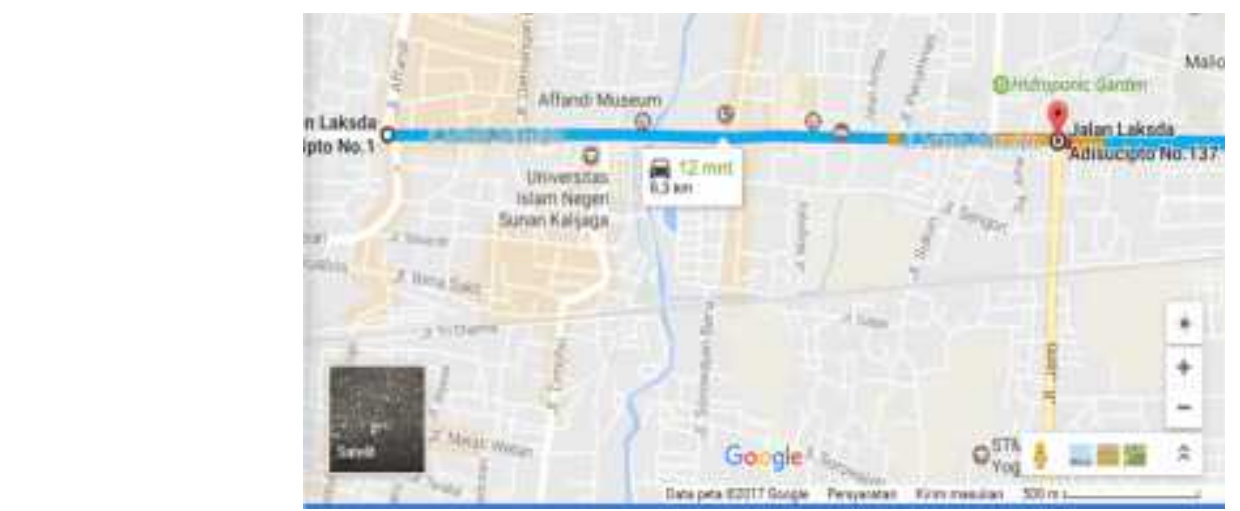

Gambar 7. Denah Lokasi Jalan Solo (Laksda Adisucipto, 6,3 km) di Kota Yogyakarta Sumber: Google maps, 2017

\section{Pengumpulan Data}

Data primer untuk analisis diperoleh dengan cara pengamatan/survei secara langsung di lokasi penelitian di ruas Jalan Abu Bakar Ali, Jalan Malioboro, dan Jalan Solo di Kota Yogyakarta dan survei wawancara responden pengguna jalan dengan kuisioner. Data sekunder yang digunakan untuk mendukung analisis antara lain, yaitu (a) peta ruas jalan dan kondisi di sekitar lokasi studi, (b) asumsi-asumsi dalam standar desain, (c) standar tentang marka, rambu, penerangan, drainasi, dan sebagainya, serta (d) laporan studi terkait. Metode analisis kuantitatif dan kualitatif sesuai SLFJ dan SRTH diterapkan secara rasional.

Pada penelitian analisis kondisi jalan ini ada beberapa tolok ukur minimal yang harus dicapai, beberapa tolok ukur tersebut dapat dicari dan diketahui dengan cara melakukan pengujian, olah data dan survei lapangan. Pada penelitian ini hanya dilakukan kegiatan survei lapangan dan pengolahan data. Untuk kegiatan survei dan pengolahan data digunakan beberapa alat seperti: formulir survei kondisi jalan, alat tulis, meteran, laptop, kamera, dan alat pelindung diri. 
Rangkaian urutan penelitian ini dibagi menjadi beberapa tahap yaitu:

1 Tahap persiapan, pada tahap ini menentukan konsep dan tujuan identifikasi menggunakan studi literatur yang menunjang penelitian di lokasi jalan Abu Bakar Ali. Adapun studi literatur adalah Peraturan Menteri PU. NO. 5/PRT/M/2008, Peraturan Walikota Yogyakarta N0.6 Th 2010, Peraturan Menteri PU No.11/PRT/M/2010, dan tata cara penyusunan pemeliharaan jalan kota.

2 Tahap pengumpulan data, tahap ini terdiri pengumpulan data primer, sekunder, dan pada jalan Abu bakar ali jenis data yang diperoleh adalah jenis, distribusi, topologi, ukuran, dan elemen lanskap jalan.

3 Tahap analisis, tahap ini analisis yang dilakukan adalah mengidentifikasi karakteristik ruang terbuka hijau pada jalan Abu Bakar Ali sesuai dengan standar tata cara penyusunan pemeliharaan jalan kota dan proses evaluasi yang dilakukan terhadap kualitas dan kuantitas masing-masing ruang terbuka hijau.

a. Evaluasi kualitas ruang tebuka hijau, analisis digunakan untuk mengetahui kualitas ruang terbuka hijau yang terdapat pada lokasi penelitian.

b. Evaluasi kuantitas ruang terbuka hijau, analisis ini berfokus pada identifikasi luasan ruang terbuka hijau eksiting tapak, yaitu dengan membandingkan luas ruang terbuka hijau yang sudah ada dengan standar yang telah ditetapkan.

4 Tahap rekomendasi adalah menyimpulkan analisis yang didapatkan sesuai dengan standar laik fungsi jalan dan menyusun arahan konsep desain pengembangan ruang terbuka hijau.

\section{Skala Likert}

Skala likert yang dikenalkan pertama kali oleh Rensis Likert pada tahun 1932, merupakan metode skala bipolar yang mengukur semua bentuk tanggapan baik positif maupun negatif terhadap suatu pernyataan. Skala likert menjadi metode yang paling umum digunakan dalam survei/penelitian. Responden menentukan tingkat persetujuan terhadap suatu pernyataan dengan memilih salah satu dari pilihan yang tersedia. Setiap pilihan mempunyai bobot nilai yang berbeda sesuai dengan pernyataan tersebut. Sampel merupakan bagian dari populasi, sementara populasi adalah keseluruhan elemen atau unsur yang akan diteliti. Contoh skala likert dan bobotnya yaitu sangat setuju $(\mathrm{SS})=5$, setuju $(\mathrm{S})=4$, ragu $(\mathrm{R})=3$, tidak setuju $(\mathrm{TS})=2$, dan sangat tidak setuju $(\mathrm{STS})=1$.

Interval kategori penilaian keputusan berdasarkan Likert diperlihatkan pada Tabel adalah: 
Tabel 2. Interval Kategori Penilaian Keputusan Berdasarkan Skala Likert

\begin{tabular}{lll}
\hline Interval & Persetujuan & Penilaian/Kondisi \\
\hline $4,20-5,00=$ & Sangat Setuju (SS) & Sangat baik (SB) \\
$3,40-4,19=$ & Setuju (S) & Baik (B) \\
$2,60-3,39=$ & Ragu (R) & Cukup (C) \\
$1,80-2,59=$ & Tidak Setuju (TS) & Tidak baik (KB) \\
$1,00-1,79=$ & Sangat Tidak Setuju (STS) & Sangat tidak baik (STB) \\
\hline
\end{tabular}

\section{HASIL DAN PEMBAHASAN}

\section{Nilai Kondisi Perkerasan}

Survei kondisi jalan yang dilakukan di tiga lokasi masing-masing 11 unit sampel, 12 unit sampel, dan 10 unit sampel (Jalan Solo, Maliboro, dan Abu Bakar Ali). Nilai PCI pada satu ruas dicari dengan menghitung rata-rata nilai $P C I$ pada semua sampel unit. Hasil nilai $P C I$ disajikan pada Tabel 3. Nilai PCI ruas Jalan Solo, Jalan Malioboro, dan Jalan Abu Bakar Ali semua termasuk dalam interval 86-100, sehingga termasuk kategori sempurna/excellent.

Tabel 3. Nilai PCI pada Ruas Jalan

\begin{tabular}{|c|c|c|c|c|c|c|c|c|}
\hline $\begin{array}{l}\text { No.Unit } \\
\text { Sampel }\end{array}$ & $\begin{array}{l}\text { Luas Unit } \\
\text { Sampel } \\
\left(\mathrm{m}^{2}\right)\end{array}$ & $\begin{array}{l}\text { Nilai } \\
P C I\end{array}$ & $\begin{array}{l}\text { No.Unit } \\
\text { Sampel }\end{array}$ & $\begin{array}{l}\text { Luas Unit } \\
\text { Sampel } \\
\left(\mathrm{m}^{2}\right)\end{array}$ & $\begin{array}{l}\text { Nilai } \\
P C I\end{array}$ & $\begin{array}{l}\text { No.Unit } \\
\text { Sampel }\end{array}$ & $\begin{array}{l}\text { Luas Unit } \\
\text { Sampel } \\
\left(\mathrm{m}^{2}\right)\end{array}$ & $\begin{array}{l}\text { Nilai } \\
P C I\end{array}$ \\
\hline \multicolumn{3}{|c|}{ Jalan Solo } & \multicolumn{3}{|c|}{ Jalan Malioboro } & \multicolumn{3}{|c|}{ Jalan Abu Bakar Ali } \\
\hline 1 & 361.5 & 92 & 1 & 350 & 100 & 1 & 375 & 100 \\
\hline 2 & 361.5 & 99 & 2 & 350 & 100 & 2 & 375 & 89 \\
\hline 3 & 361.5 & 95 & 3 & 350 & 96 & 3 & 375 & 84 \\
\hline 4 & 361.5 & 100 & 4 & 350 & 95 & 4 & 375 & 93 \\
\hline 5 & 361.5 & 100 & 5 & 350 & 99 & 5 & 375 & 84 \\
\hline 6 & 361.5 & 100 & 6 & 350 & 100 & 6 & 375 & 89 \\
\hline 7 & 361.5 & 100 & 7 & 350 & 94 & 7 & 375 & 88 \\
\hline 8 & 361.5 & 100 & 8 & 350 & 90 & 8 & 375 & 81 \\
\hline 9 & 361.5 & 100 & 9 & 350 & 96 & 9 & 375 & 84 \\
\hline 10 & 361.5 & 95 & 10 & 350 & 99 & 10 & 375 & 86 \\
\hline 11 & 361.5 & 96 & 11 & 350 & 100 & & Total $=$ & 878 \\
\hline \multirow{2}{*}{\multicolumn{2}{|c|}{$\begin{array}{r}\text { Total }= \\
\text { PCI rata-rata }=\end{array}$}} & 1077 & 12 & 350 & 99 & & CI rata-rata $=$ & 87,8 \\
\hline & & 97,9 & \multicolumn{2}{|c|}{$\begin{array}{r}\text { Total } \\
\text { PCI rata-rata }\end{array}$} & 1168 & & & \\
\hline
\end{tabular}

\section{Kondisi Jarak Pandang Operasional}

Hasil perhitungan jarak pandang (Lihat Tabel 4) menunjukkan bahwa jarak pandang merupakan aspek teknis geometrik jalan di ketiga lokasi ruas jalan menunjukkan bahwa jarak pandang henti maupun mendahului secara operasional lebih pendek dari pada jarak pandang rencana. 
Tabel 4. Hasil perhitungan jarak pandang Jalan Solo, Malioboro, dan Abu Bakar Ali

\begin{tabular}{|c|c|c|c|c|c|}
\hline \multirow[b]{2}{*}{$\begin{array}{l}\text { Jenis } \\
\text { Kendaraan }\end{array}$} & \multicolumn{2}{|c|}{ Jarak Pandang Henti } & \multicolumn{2}{|c|}{ Jarak Pandang Mendahului } & \multirow{2}{*}{$\begin{array}{l}\text { Lokasi/Kec rencana/Syarat Jarak } \\
\text { pandang Min }\end{array}$} \\
\hline & $\begin{array}{l}\text { Rencana } \\
\text { (meter) }\end{array}$ & $\begin{array}{l}\text { Operasional } \\
\text { (meter) }\end{array}$ & $\begin{array}{l}\text { Rencana } \\
\text { (meter) }\end{array}$ & $\begin{array}{l}\text { Operasional } \\
\text { (meter) }\end{array}$ & \\
\hline Sepeda Motor & $110,8(>75)$ & 94,5 & $416,9(>350)$ & 365,5 & Jalan Solo (Vr = 60 km/jam) \\
\hline Mobil \& Truk & $110,8(>75)$ & 52,2 & $416,9(>350)$ & 235,6 & $>\operatorname{Min} 75 \mathrm{~m}$ \\
\hline Sepeda Motor & $110,8(>75)$ & 73,4 & $416,9(>350)$ & 304,5 & Jl. Malioboro $(\mathrm{Vr}=60 \mathrm{~km} / \mathrm{jam})$ \\
\hline Mobil \& Truk & $110,8(>75)$ & 39,9 & $416,9(>350)$ & 201,2 & $>\operatorname{Min} 75 \mathrm{~m}$ \\
\hline Sepeda Motor & $70,4(>55)$ & 65,4 & $320,4(>250)$ & 205,7 & Jl. Abu Bakar Ali $(\mathrm{Vr}=50 \mathrm{~km} / \mathrm{jam})$ \\
\hline Mobil \& Truk & $70,4(>55)$ & 35,6 & $320,4(>250)$ & 193,4 & $>\operatorname{Min} 55 \mathrm{~m}$ \\
\hline
\end{tabular}

\section{Karakteristik Responden pada Survei Kuisioner}

Karakteristik responden pada penelitian ini dibagi menjadi 3 karakteristik yaitu jenis kelamin, usia, dan pendidikan terakhir.

\begin{tabular}{cccc}
\multicolumn{4}{c}{ Tabel 5. Responden berdasarkan jenis kelamin } \\
\hline $\begin{array}{c}\text { Jenis } \\
\text { Kelamin }\end{array}$ & $\begin{array}{c}\text { Jumlah } \\
(\text { Orang) }\end{array}$ & $\begin{array}{c}\text { Persentase } \\
(\%)\end{array}$ & Lokasi \\
\hline L & 31 & $62 \%$ & Jalan Solo \\
P & 19 & $38 \%$ & \\
\hline L & 19 & $48 \%$ & Jalan Malioboro \\
P & 21 & $53 \%$ & \\
\hline L & 22 & $44 \%$ & Jalan Abu Bakar Ali \\
P & 28 & $54 \%$ & \\
\hline
\end{tabular}

Tabel 6. Karakteristik Responden Berdasarkan Usia

\begin{tabular}{|c|c|c|c|c|c|c|c|}
\hline \multirow{2}{*}{$\begin{array}{c}\text { Usia } \\
\text { (Tahun) }\end{array}$} & $\begin{array}{l}\text { Jumlah } \\
\text { (Orang) }\end{array}$ & $\begin{array}{c}\text { Persentase } \\
(\%)\end{array}$ & $\begin{array}{l}\text { Jumlah } \\
\text { (Orang) }\end{array}$ & $\begin{array}{c}\text { Persentase } \\
(\%)\end{array}$ & $\begin{array}{l}\text { Jumlah } \\
\text { (Orang) }\end{array}$ & $\begin{array}{c}\text { Persentase } \\
(\%)\end{array}$ & \multirow[t]{2}{*}{ Kategori } \\
\hline & \multicolumn{2}{|c|}{ Jalan Solo } & \multicolumn{2}{|c|}{ Jalan Malioboro } & \multicolumn{2}{|c|}{ Jl. Abu Bakar Ali } & \\
\hline$\leq 18$ & 1 & $2 \%$ & 3 & $8 \%$ & 3 & $6 \%$ & remaja awal \\
\hline $19-25$ & 36 & $72 \%$ & 31 & $78 \%$ & 30 & $60 \%$ & remaja akhir \\
\hline $26-35$ & 11 & $22 \%$ & 6 & $15 \%$ & 14 & $28 \%$ & dewasa awal \\
\hline $36-45$ & 2 & $2 \%$ & 0 & $0 \%$ & 3 & $6 \%$ & dewasa akhir \\
\hline $46-55$ & 0 & $0 \%$ & 0 & $0 \%$ & 0 & $0 \%$ & lansia awal \\
\hline$\geq 56$ & 0 & $0 \%$ & 0 & $0 \%$ & 0 & $0 \%$ & lansia akhir \\
\hline
\end{tabular}

Tabel 6. Karakteristik Responden Berdasarkan Usia

\begin{tabular}{ccccccc}
\hline \multirow{2}{*}{$\begin{array}{c}\text { Pendidikan } \\
\text { Terakhir }\end{array}$} & $\begin{array}{c}\text { Jumlah } \\
\text { (Orang) }\end{array}$ & $\begin{array}{c}\text { Persentase } \\
(\%)\end{array}$ & $\begin{array}{c}\text { Jumlah } \\
\text { (Orang) }\end{array}$ & $\begin{array}{c}\text { Persentase } \\
(\%)\end{array}$ & $\begin{array}{c}\text { Jumlah } \\
\text { (Orang) }\end{array}$ & $\begin{array}{c}\text { Persentase } \\
(\%)\end{array}$ \\
\cline { 2 - 7 } SD & \multicolumn{2}{c}{ Jalan Solo } & \multicolumn{2}{c}{ Jalan Malioboro } & Jl. Abu Bakar Ali \\
\hline SMP & 0 & $0 \%$ & 0 & $0 \%$ & 0 & $0 \%$ \\
SMA/SMK & 0 & $0 \%$ & 0 & $0 \%$ & 0 & $0 \%$ \\
Diploma & 23 & $46 \%$ & 21 & $53 \%$ & 28 & $56 \%$ \\
Sarjana & 14 & $28 \%$ & 7 & $18 \%$ & 12 & $24 \%$ \\
\hline
\end{tabular}

\section{Pengetahuan Responden Tentang Pemanfaatan Ruang Jalan}

Total nilai rata-rata pengetahuan responden tentang pemanfaatan ruang jalan adalah 3,4 dan nilai tanggapan responden adalah Setuju (S). 
Tabel 7. Tanggapan Responden Tentang Pemanfaatan Ruang Jalan

\begin{tabular}{llrr}
\hline No & \multicolumn{1}{c}{ Daftar Pernyataan } & Rata-rata & Ket \\
\hline 1 & $\begin{array}{l}\text { Mengembalikan fungsi trotoar untuk pedestrian dan bukan tempat } \\
\text { berjualan. }\end{array}$ & 4,20 & $\mathrm{SS}$ \\
2 & $\begin{array}{l}\text { Pengendara sepeda motor menggunakan trotoar pada saat jalan } \\
\text { macet. }\end{array}$ & 3,00 & $\mathrm{R}$ \\
3 & $\begin{array}{l}\text { Larangan parkir kendaraan di badan jalan. } \\
\text { Memelihara fasilitas kebersihan, keamanan dan kenyamanan di ruang } \\
\text { jalan. }\end{array}$ & 3,68 & $\mathrm{~S}$ \\
& Rata-rata $=$ & 3,5 & $\mathrm{~S}$ \\
\hline
\end{tabular}

Catatan: $\mathrm{SS}=$ sangat setuju, $\mathrm{S}=$ setuju, $\mathrm{R}=$ ragu-ragu, $\mathrm{TS}=$ tidak setuju, $\mathrm{STS}=$ sangat tidak setuju

\section{Kondisi Laik Fungsi Jalan}

Dari analisis kondisi ruas Jalan Solo menggunakan formulir pedoman teknis pelaksanaan laik fungsi jalan sebanyak 48 komponen penilaian, dihasilkan penetapan kategori setiap kelaikan teknis jalan seperti dapat dilihat pada Tabel 8, Tabel 9, Tabel 10, dan Gambar 8. Penilaian aspek teknis ruas Jalan Solo, Jalan Malioboro, dan Jalan Abu Bakar Ali, ketigaketiganya termasuk dalam kategori LS dikarenakan pada beberapa komponen jalan yang diuji masih terdapat rekomendasi teknis yang harus dipenuhi agar suatu ruas jalan tersebut dapat dikategorikan LF (laik fungsi).

\section{Tabel 8. Rekapitulasi Evaluasi Aspek Kelaikan di Tiga Lokasi Observasi}

\begin{tabular}{|c|c|c|c|c|}
\hline \multirow[b]{2}{*}{ No. } & \multirow[b]{2}{*}{ Aspek Kelaikan yang Dievaluasi } & \multicolumn{3}{|c|}{ Kategori Kelaikan } \\
\hline & & $\begin{array}{l}\text { Jalan } \\
\text { Abu } \\
\text { Bakar } \\
\text { Ali }\end{array}$ & $\begin{array}{l}\text { Jalan } \\
\text { Malioboro }\end{array}$ & $\begin{array}{l}\text { Jalan } \\
\text { Solo }\end{array}$ \\
\hline 1. & Teknis Geometrik Jalan & LS & LS & LS \\
\hline 2. & Teknis Struktur Perkerasan Jalan & LS & LF & $\mathrm{LF}$ \\
\hline 3. & Teknis Struktur Bangunan Pelengkap Jalan & LS & LS & LS \\
\hline 4. & Teknis Pemanfaatan Bagian-Bagian Jalan & $\mathrm{LF}$ & LS & LS \\
\hline 5. & Teknis Penyelenggaraan Manajemen dan Rekayasa Lalu-lintas & LS & LS & LS \\
\hline 6. & $\begin{array}{l}\text { Teknis Perlengkapan Jalan yang Terkait Langsung dengan Pengguna } \\
\text { Jalan }\end{array}$ & LS & LS & LS \\
\hline 7. & $\begin{array}{l}\text { Teknis Perlengkapan Jalan yang Tidak Terkait Langsung dengan } \\
\text { Pengguna Jalan }\end{array}$ & LS & LS & LS \\
\hline \multicolumn{2}{|r|}{ Penetapan kategori kelaikan teknis jalan } & $\mathbf{L S}$ & $\mathbf{L S}$ & $\mathbf{L S}$ \\
\hline
\end{tabular}

Tabel 9. Hasil Observasi Jumlah Komponen sesuai Kategori di Tiap Lokasi Penelitian

\begin{tabular}{|c|c|c|c|c|c|c|c|}
\hline \multirow[b]{2}{*}{ No } & \multirow[b]{2}{*}{ Kategori } & \multicolumn{2}{|l|}{ Jalan Abu Bakar Ali } & \multicolumn{2}{|l|}{ Jalan Maliboro } & \multicolumn{2}{|l|}{ Jalan Solo } \\
\hline & & Jumlah komponen & $(\%)$ & Jumlah komponen & $(\%)$ & Jumlah komponen & $(\%)$ \\
\hline a. & $\mathrm{LF}$ & 14 & 29 & 17 & 35 & 20 & 42 \\
\hline b. & LT & 1 & 2 & 2 & 4 & 14 & 29 \\
\hline c. & LS & 20 & 42 & 21 & 44 & 1 & 2 \\
\hline d. & TLF & 0 & 0 & 0 & 0 & 0 & 0 \\
\hline e. & $\begin{array}{l}\text { Tidak tersedia/ } \\
\text { diperlukan }\end{array}$ & 13 & 27 & 8 & 17 & 13 & 27 \\
\hline & Total $=$ & 48 & 100 & 48 & 100 & 48 & 100 \\
\hline
\end{tabular}




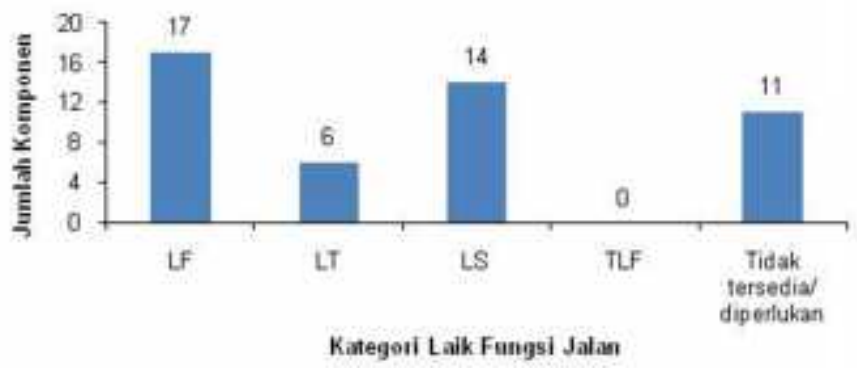

Gambar 8. Hasil Observasi Jumlah Komponen setiap Kategori

Tabel 10. Kegiatan Pemeliharaan Lanskap Jalan

\begin{tabular}{|c|c|c|c|}
\hline No. & Kegiatan Pemeliharaan & $\begin{array}{l}\text { Frekuesi pemeliharaan di } \\
\text { lokasi }\end{array}$ & $\begin{array}{c}\text { Frekuensi jadwal } \\
\text { pemeliharaan }\end{array}$ \\
\hline 1 & Penyiraman & 1 kali/hari & 1 kali/hari \\
\hline 2 & Pemangkasan rumput & 1 kali/bulan & 1 kali/bulan \\
\hline 3 & Pemangkasan semak & $1 \mathrm{kali} / 2$ bulan & $1 \mathrm{kali} / 2$ bulan \\
\hline 4 & Pemangkasan pohon & $\begin{array}{l}\text { Sesuai jadwal } \\
\text { pemeliharaan }\end{array}$ & $1 \mathrm{kali} / 6$ bulan \\
\hline 5 & Pengendalian hama & Jika terjadi serangan hama & $1 \mathrm{kali} / 6$ bulan \\
\hline 6 & Pemupukan & $1 \mathrm{kali} / 3$ bulan & 1 kali/3bulan \\
\hline 7 & $\begin{array}{l}\text { Pemeriksaan saluran } \\
\text { gorong gorong }\end{array}$ & 1 kali/bulan & $1 \mathrm{kali} / \mathrm{bulan}$ \\
\hline 8 & Penyapuan (sapu jalan) & 1 kali/hari & 1 kali/hari \\
\hline 9 & $\begin{array}{l}\text { Pembersihan dari } \\
\text { sampah hijau }\end{array}$ & $\begin{array}{l}\text { Sesuai jadwal } \\
\text { pemangkasan pohon }\end{array}$ & $\begin{array}{l}\text { Sesuai jadwal } \\
\text { pemangkasan pohon }\end{array}$ \\
\hline
\end{tabular}

\section{Kondisi Lingkungan dan Konsep Desain RTH di Koridor Jalan}

Kuesioner yang diberikan kepada 40 responden ditujukan untuk mengevaluasi pengelolaan dan pemeliharaan fasilitas, sarana dan prasarana. Kuesioner meliputi lima pernyataan mengenai pengelolaan dan pemeliharaan yang perlu ditanggapi oleh responden. Hasil jawaban dari responden dapat diketahui dari nilai rata-ratanya (Lihat Tabel 11). Pernyataan responden mengenai evaluasi pengelolaan dan pemeliharaan fasilitas, sarana dan prasarana adalah Baik (B) dengan nilai rata-rata dari seluruh pernyataan adalah sebesar 3,7 dan berada pada interval 3,40-4,19, namun terdapat tiga pernyataan yang sebagian besar responden memilih Cukup $(\mathrm{C})$.

Tabel 11. Tanggapan Responden tentang Kondisi Ruang Jalan dan Lingkungan Sekitarnya

\begin{tabular}{lllccccc}
\hline \multirow{2}{*}{ No } & Daftar Pernyataan & \multicolumn{2}{c}{ Jalan Solo } & \multicolumn{2}{c}{ Jl. Malioboro } & \multicolumn{2}{c}{ Jl. Abu Bakar Ali } \\
\cline { 3 - 7 } & Rata-rata & Ket & Rata-rata & Ket & Rata-rata & Ket \\
\hline 1 & $\begin{array}{l}\text { Bagaimana menurut anda tentang } \\
\text { penataan ruang pedestrian }\end{array}$ & 4,00 & B & 4,00 & B & 4,5 & SB \\
2 & $\begin{array}{l}\text { Bagaimana menurut anda tentang } \\
\text { keamanan pedestrian }\end{array}$ & 3,35 & C & 3,35 & $\mathrm{C}$ & 3,9 & B \\
3 & $\begin{array}{l}\text { Bagaimana menurut anda tentang } \\
\text { kenyamanan pedestrian }\end{array}$ & 3,25 & C & 3,25 & C & 4,4 & SB \\
4 & $\begin{array}{l}\text { Bagaimana menurut anda terhadap } \\
\text { fasilitas pada kawasan seperti pohon }\end{array}$ & 3,20 & C & 3,20 & C & 4,1 & B
\end{tabular}




\begin{tabular}{l}
$\begin{array}{l}\text { peneduh, kursi, papan informasi, dan } \\
\text { toilet } \\
\text { Bagaimana menurut anda tentang } \\
\text { keindahan kawasan pedestrian }\end{array}$ \\
\hline Rata-rata $=$
\end{tabular}

Catatan: $\mathrm{SB}=$ sangat baik, $\mathrm{B}=$ baik, $\mathrm{C}=$ cukup, $\mathrm{TB}=$ tidak baik, $\mathrm{STB}=$ sangat tidak baik

Ruang terbuka hijau di ketiga lokasi Jalan Abu Bakar Ali, Jalan Malioboro dan Jalan Solo, disesuaikan dengan kebutuhan kawasan lingkunganya seperti jalur hijau jalan, jalur hijau trotoar, dan area hijau. Caranya adalah memaksimumkan luasan lahan tersedia untuk menambah desain jalan yang berbasis ruang terbuka hijau. Keberadaan ruang terbuka hijau jalan sangat diperlukan dalam kawasan kota, keberadaan jalur hijau jalan menjadi urat nadi kawasan perkotaan, selain untuk memenuhi proporsi ideal bagi ruang terbuka hijau. Selain itu juga berfungsi sebagai penghubung antar ruang terbuka hijau lainnya. Dari observasi dan analisis diperoleh beberapa faktor yang menjadi penyebab kurangnya perawatan ruang terbuka hijau, yaitu meningkatnya kebutuhan masyarakat akan lahan parkir, meningkatnya intensitas kepadatan penduduk serta perubahan fungsi lahan di sekitar ruang jalan. Gambar 9 dan 10 merupakan contoh konsep desain ruang terbuka hijau di koridor jalan.

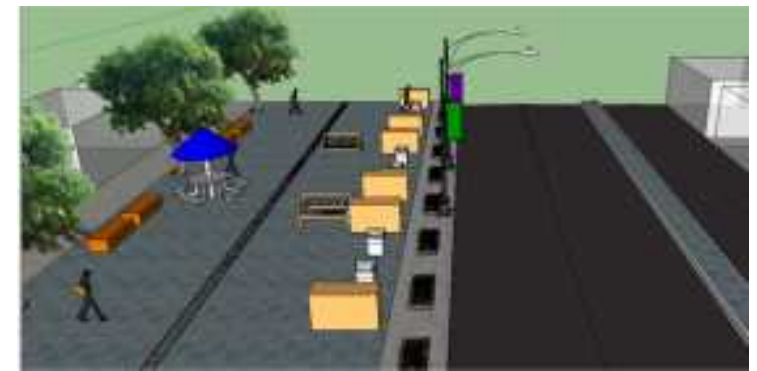

Gambar 9. Konsep Desain RTH di Jalan Malioboro

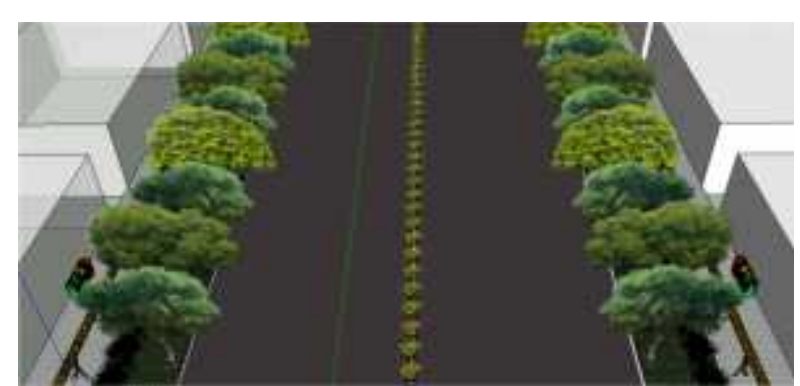

Gambar 10. Konsep Desain RTH di Jalan

Abu Bakar Ali

\section{KESIMPULAN}

Dari analisis dapat disimpulkan antara lain, bahwa pengetahuan dan persepsi responden tentang pemanfaatan ruang jalan dan evaluasi kondisi lingkungan sekitar jalan di ketiga lokasi diperoleh nilai rata-rata 3,4; 3,52; dan 4,2 dengan kategori Baik. Di lokasi Jalan Abu Bakar Ali responden selanjutnya menjawab Setuju (skor 3,5) diperlukan penambahan fasilitas dan pemeliharaan fasilitas dan landskap RTH. Pengelolaan dan pemeliharaan prasarana, sarana dan fasilitas RTH Jalan Abu Bakar Ali, Jalan Malioboro dan Jalan Solo sudah dilakukan oleh Dinas Tata Kota Yogyakarta, terorganisasi dan terjadwal dengan baik. Dengan panduan teknis pelaksanaan evaluasi laik fungsi jalan di ruas Jalan Abu Bakar Ali (kolektor sekunder), Jalan Malioboro (arteri sekunder), dan Jalan Solo (arteri sekunder) ketiganya dikategorikan Laik Fungsi Bersyarat (LS), yang artinya jalan tersebut belum 
memenuhi sebagian persyaratan teknis laik fungsi jalan dalam hal pemanfaatan ruang bagianbagian jalan, atau masih ada rekomendasi teknis yang harus dipenuhi agar ruas jalan tersebut dapat dikategorikan Laik Fungsi (LF). Di lokasi studi terbukti belum berfungsinya Ruang Manfaat Jalan (Rumaja) yang ditandai dengan masih banyak bangunan permanen maupun tidak permanen pada daerah Rumaja. Konsep desain pengelolaan dan pemeliharaan prasarana ruang jalan umum perlu didasarkan pada prinsip memaksimumkan fungsi jalan (sesuai SLFJ) dan pemenuhan fungsi ruang terbuka hijau pada trotoar dengan penghijauan area sekitar (sesuai SRTH).

\section{UCAPAN TERIMA KASIH}

Ucapan terimakasih disampaikan kepada Departemen Teknik Sipil Sekolah Vokasi UGM atas dukungan pendanaan untuk penelitian ini, Data sekunder diperoleh dari Instansi Direktorat Jendral Bina Marga Satker PJN Provinsi DIY. Kepada para surveyor dari mahasiswa antara lain, Mohamad Posya Pratista, Prasetyo Utomo, Muhammad Abror, dan Aswin Kurniawan diucapkan terima kasih. Dosen Departemen Teknik Sipil Sekolah Vokasi UGM dan teman-teman yang turut serta dalam diskusinya membantu selesainya penelitian ini.

\section{DAFTAR PUSTAKA}

Direktorat Jendral Bina Marga, 1990, Tata Cara Penyusunan Program Pemeliharaan Jalan Kota, Nomor 18, Menteri Pekerjaan Umum, Jakarta.

Direktorat Jendral Bina Marga, 2012, Panduan Teknis Uji Laik Fungsi Jalan, Kementerian Pekerjaan Umum, Jakarta.

Effendi, D.M., dan Firdaus, O., 2016, Analisis Keselamatan Jalan pada Ruas Jalan Ahmad Yani dalam Kota Palangkaraya, Karya Tulis, Universitas Bangka Belitung, Merawang.

Oktaviarni, S.I., 2008, Pengelolaan Pemeliharaan Lanskap di Kawasan Permukiman Sentul City, Skripsi, Institut Pertanian Bogor, Bogor.

Peraturan Menteri Pekerjaan Umum, 2008, Penyediaan dan Pemanfaatan Ruang Terbuka Hijau di Kawasan Perkotaan, Nomor: 05/PRT/M/2008, Menteri Pekerjaan Umum, Jakarta.

Peraturan Menteri Pekerjaan Umum, 2010, Tata Cara dan Persyaratan Laik Fungsi Jalan, Nomor: 11/PRT/M/2010, Menteri Pekerjaan Umum, Jakarta.

Peraturan Menteri Pekerjaan Umum, 2011, Persyaratan Teknis Jalan dan Kriteria Perencanaan Teknis Jalan, Nomor: 19 /PRT/M/2011, Menteri Pekerjaan Umum, Jakarta.

Peraturan Walikota Yogyakarta, 2010, Penyediaan Ruang Terbuka Hijau Privat, Nomor: 08/2010, Walikota Yogyakarta, Yogyakarta. 
Putri, D.G., 2010, Konsep Penataan Ruang Terbuka Hijau di Kawasan Pusat Kota Ponorogo, Skripsi, Institut Teknologi Sepuluh November, Surabaya.

Republik Indonesia, 2004, Undang-Undang Tentang Jalan, UU No. 38 Tahun 2004, Pemerintah Republik Indonesia, Jakarta.

Hardiatmo, H. C., 2015, Pemeliharaan Jalan Raya, Edisi Kedua, Gadjah Mada University Press, Yogyakarta.

Sukirman, Silvia, 1994, Dasar-dasar Perencanaan Geometrik Jalan, Penerbit Nova, Bandung. 